\title{
Gilles Brougère et Giulia Fabbiano (dir.), Apprentissages en situation touristique
} coll. "Éducation et didactiques", Septentrion Presses universitaires, 2014

\section{Philippe Violier}

\section{OpenEdition}

\section{Journals}

Édition électronique

URL : http://journals.openedition.org/tourisme/155

DOI : 10.4000/tourisme.155

ISSN : 2492-7503

\section{Éditeur}

Éditions touristiques européennes

\section{Édition imprimée}

Date de publication : 1 juin 2014

Pagination : 103-104

ISSN : 2109-5671

\section{Référence électronique}

Philippe Violier, "Gilles Brougère et Giulia Fabbiano (dir.), Apprentissages en situation touristique », Mondes du Tourisme [En ligne], 9 | 2014, mis en ligne le 30 septembre 2015, consulté le 22 septembre 2020. URL : http://journals.openedition.org/tourisme/155 ; DOI : https://doi.org/10.4000/tourisme. 155

Ce document a été généré automatiquement le 22 septembre 2020

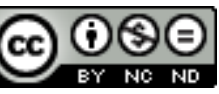

Mondes du tourisme est mis à disposition selon les termes de la licence Creative Commons Attribution - Pas d'Utilisation Commerciale - Pas de Modification 4.0 International. 


\title{
Gilles Brougère et Giulia Fabbiano (dir.), Apprentissages en situation
}

\section{touristique}

\author{
coll. "Éducation et didactiques", Septentrion Presses universitaires, 2014
}

Philippe Violier

\section{RÉFÉRENCE}

Gilles Brougère et Giulia Fabbiano (dir.), Apprentissages en situation touristique, coll.

“Éducation et didactiques", Septentrion Presses universitaires, 2014.

1 Cet ouvrage lumineux devrait être recommandé à tous, depuis les élus de la Nation confrontés au maquis du calendrier scolaire (même si les vacances, ce n'est pas seulement le tourisme) jusqu'aux intellectuels prompts à moquer les touristes. Le tourisme est "une pratique ouvertement éducative", affirment d'emblée, en page 11 de leur introduction, les directeurs de cet ouvrage. Leur projet s'inscrit de fait dans le prolongement de Tourisme 1. Lieux communs (Équipe MIT), publié en 2002. Dans le cadre de cette démarche visant à élaborer une approche scientifique du tourisme qui rompe avec les discours péjoratifs de nombre d'intellectuels, nous avions posé que le tourisme constitue un moment d'apprentissage, que la rupture avec le quotidien rend l'individu disponible pour des expériences et justifié par-là le concept de "re-création". Si ensuite nous avons travaillé la question des apprentissages touristiques, "on ne naît pas touriste, on le devient" - ce qui souligne qu'être touriste n'est pas naturel mais socialement construit -, les questions de l'apprentissage au-delà du tourisme et au-delà de la relation de l'adulte à l'enfant sont restées. C'est cette zone d'ombre que cet ouvrage vient partiellement combler en abordant cinq dimensions de l'apprentissage en situation touristique: temporalité, cadres, morphologie des apprentissages (autodidaxie, fortuit, de socialisation), support (guides, accompagnateurs, animateurs), 
écart entre projet des organisateurs et aspiration des touristes. Cet apport aux tourism studies intéressera aussi les spécialistes des sciences de l'éducation qui s'interrogent sur les apprentissages dans les contextes informels.

2 L'introduction remarquable donne toute sa cohérence à l'ouvrage, fruit d'un travail d'équipe auquel ont été incorporées, de manière complémentaire, deux contributions qui éclairent parfaitement la réflexion. L'ensemble revêt de fait une grande cohérence peu commune dans un ouvrage collectif. Le choix, justifié, de travailler la question à partir du tourisme social y contribue. La visée ouvertement éducative du tourisme social pourrait limiter le propos. Mais les auteurs soulignent la distance entre le projet des organisateurs et les pratiques des individus, si bien que ce choix, au regard de l'ambition, apparaît comme un souci de clarté et non une facilité. Les auteurs analysent d'ailleurs finement les conditions de réalisation et les méthodes qualitatives mises en œuvre, de 2008 à 2009, dans sept villages de vacances. Ensuite, l'introduction est aussi une conclusion, mais le texte gagne en cohérence et du coup peut être lu par le lecteur avant de picorer dans l'ouvrage, sans respecter nécessairement le plan proposé - il faut bien reconnaître que travailler dans un champ plutôt que dans une science nous amène à recourir à des modalités efficaces de lecture. En effet, Gilles Brougère et Giulia Fabbiano livrent les principaux acquis de la réflexion collective et exposent les modalités de l'apprentissage en situation touristique.

3 L'ouvrage est organisé en trois parties. Dans la première, Giulia Fabbiano, Anne-Lise Ulmann et Sylvain Pattieu démontrent dans trois textes que les organisations du tourisme social échouent, au moins partiellement, dans leur projet éducatif : parce que les militants éloignés par leurs parcours des populations qu'ils accueillent ne les comprennent pas; parce que le modèle économique contraint les organisations à s'appuyer sur un personnel saisonnier peu au fait du projet; enfin, parce que les individus touristes aspirent à une détente elle-même nécessaire, comme condition de la construction des apprentissages. Les auteurs analysent notamment que les processus d'apprentissage se mettent en œuvre autant pendant les moments creux que pendant les activités dûment inscrites au programme, et autant entre les touristes eux-mêmes que par guidage ou accompagnement.

4 La seconde partie explore de manière approfondie les modalités de l'apprentissage en situation touristique. Gilles Brougère développe la question du guidage des touristes. Nathalie Roucous et Denis Adam montrent comment la cohabitation des familles, par le tourisme, rend visibles des manières de faire différentes (notamment au sujet des relations entre parents et enfants) et, par là même, met au jour une palette de possibilités alternatives parmi lesquelles les parents peuvent puiser pour faire face à des situations d'éducation variées. Hélène Bézille souligne comment l'agencement du lieu, le village de vacances, contribue à cette circulation des expériences qui fonde l'apprentissage par les touristes eux-mêmes à l'occasion des moments de convivialité passés sur "la terrasse".

5 La troisième partie ouvre la réflexion à travers deux textes très différents et tout aussi intéressants. Giulia Fabbiano apporte une riche contribution à la question des relations au sein du système des mobilités entre le tourisme et les migrations, à travers l'exemple du "revenir" de familles des harkis. Gilles Brougère se livre à un essai d'autoethnographie qui fournit une réflexion stimulante à ceux qui s'interrogent sur la manière de mobiliser leur propre expérience touristique afin de contribuer à l'avancée des tourism studies. 
6 L'ensemble constitue donc une contribution essentielle. Nous attendons avec impatience que les auteurs sortent du tourisme social pour aborder ces questions dans d'autres contextes, car ce n'est qu'un exemple - la coprésence et le brassage relatif, induits par les situations touristiques, ne se rencontrent pas que dans le tourisme social.

\section{AUTEURS}

\section{PHILIPPE VIOLIER}

Université d'Angers [philippe.violier@univ-angers.fr] 